\title{
O edifício doente e o edifício saudável
}

\author{
Antonio Pedro Alves de Carvalho \\ Prof. Doutor, Faculdade de Arquitetura \\ Universidade Federal da Bahia (UFBA) \\ هedro@ufba.br
}

Recebido em 18 de junho de 2017

Aceito em 13 de julho de 2017

\begin{abstract}
Resumo:
A caracterização das edificações saudáveis é tratada, no presente artigo, através da análise de referências que estudam as condições físicas que induzem ao bem-estar e a recuperação de pacientes em edificações de saúde. Inicialmente discorre-se sobre as questões ambientais envolvidas na ocorrência da Síndrome do Edifício Doente, justificando a caracterização dos Edifícios Saudáveis. As características levantadas foram englobadas nos setores de higiene, conforto e sustentabilidade. Em relação à higiene, destacou-se a localização estratégica de lavatórios, o que favorece as condições de controle de infecção; a utilização de materiais de acabamento que permitam fácil limpeza e manutenção e a disponibilização de infraestrutura que garanta a segregação, guarda, coleta e tratamento de resíduos sólidos. Em relação ao conforto, são enfatizados a utilização de meios naturais de controle de temperatura, umidade, ventilação e iluminação; a disponibilidade de áreas verdes, a adoção da acessibilidade universal e o controle do ruído. A sustentabilidade em edificações para a saúde recebe ênfase quanto ao estabelecimento de condições de suprimento ininterrupto de energia e água, com a utilização de formas limpas de geração e aproveitamento. Conclui-se pela adequação dos estudos ambientais em estabelecimentos de saúde como parâmetros para a definição das condições físicas de uma Edificação Saudável.
\end{abstract}

Palavras-chave: Arquitetura hospitalar; Ambiente saudável; Ambiente e saúde.

\section{The sick building and the healthy building}

\begin{abstract}
:
The characterization of healthy buildings is addressed in this article through the analysis of references that study the physical conditions that induce the well-being and recovery of patients in health buildings. Initially, we discuss the conditions established for the occurrence of the Sick Building Syndrome, justifying the characterization of Healthy Buildings. The characteristics raised were encompassed in the sectors of hygiene, comfort and sustainability. Regarding hygiene, the strategic location of lavatories was highlighted, which favors infection control conditions; the use of finishing materials that allow easy cleaning and maintenance, and the provision of infrastructure to ensure segregation, storage, collection and treatment of solid waste. Regarding comfort, the use of natural means of temperature, humidity, ventilation and illumination control is emphasized; the availability of green areas, the establishment of universal accessibility and noise control. Sustainability in health buildings is emphasized in terms of establishing uninterrupted energy and water supply, with the use of clean forms of generation. It concludes by the adequacy of environmental studies in health facilities as parameters for the definition of physical conditions in a Healthy Building.

Keywords: Hospital architecture; Healthy environment; Environment and health.
\end{abstract}




\section{El edificio enfermo y el edificio saludable}

\section{Resumen:}

La caracterización de las edificaciones saludables es tratada en el presente artículo a través del análisis de referencias que estudian las condiciones físicas que inducen al bienestar y la recuperación de pacientes en edificaciones de salud. De primero se discurre a cerca de las condiciones establecidas para la ocurrencia del Síndrome del Edificio Enfermo, justificando la caracterización de los Edificios Saludables. Las características planteadas fueron englobadas en los sectores de higiene, confort y sostenibilidad. En cuanto a la higiene, se destacó la ubicación estratégica de lavatorios, que favorece las condiciones de control de infección; el uso de materiales de acabado que permitan fácil limpieza y mantenimiento, y la disponibilidad de infraestructura que garantice la segregación, la custodia, la recolección y el tratamiento de residuos sólidos. En cuanto al confort se enfatizan la utilización de medios naturales de control de temperatura, humedad, ventilación e iluminación; la disponibilidad de áreas verdes, el establecimiento de la accesibilidad universal y el control del ruido. La sostenibilidad en edificaciones para la salud recibe énfasis en el establecimiento de condiciones de suministro ininterrumpido de energía y agua, con la utilización de formas limpias de generación y aprovechamiento. Se concluye por la adecuación de los estudios ambientales en establecimientos de salud como parámetros para la definición de las condiciones físicas en una Edificación Saludable.

Palabras clave: Arquitectura hospitalaria, Ambiente saludable, Ambiente y salud..

\section{INTRODUÇÃO}

Podem parecer estranhas as expressões edifícios doentes ou edifícios saudáveis, pois a objetos não se colocam normalmente essas qualificações. São adjetivos, no entanto, que têm sido utilizados para, abreviadamente, indicar que existem ambientes físicos que, por suas características, são provocadores de doenças ou facilitam a cura.

A afirmação de que o ambiente é o grande responsável pelo estado de saúde humano não é nova e remonta aos gregos, particularmente a Hipócrates que, em sua obra Dos Ares, Águas e Lugares, defende a noção da saúde como um estado de equilíbrio entre o homem e seu meio ambiente (BATISTELLA, 2017). O ambiente construído, com seu caráter artificial, claramente pode expressar essa mútua influência, pois, com o domínio tecnológico crescente, tornou-se possível a criação de espaços com desequilíbrios sutis e enganadores.

Os ambientes de saúde são os mais representativos relativamente às condições físicas que influenciam seus usuários, pois são frequentados por pessoas debilitadas e sensíveis às mais leves variações das condições do espaço que os envolve. Torna-se natural, portanto, considerar o seu estudo como paradigmático para a conceituação do que seria uma edificação saudável. Na edificação para a saúde será possível detectar claramente os fatores 
prejudiciais ao equilíbrio do ser humano com seu meio, indicando aos abrigos edilícios das demais funções os principais pontos de cuidado.

No presente trabalho, serão levantadas as características de uma edificação saudável tomando por base um levantamento de referências que tratam da influência do meio ambiente de edificações assistenciais na saúde dos seus ocupantes. O objetivo proposto é a contribuição ao debate das formas de projetar e construir edificações que realmente sejam adequadas à indução do bem-estar físico e mental das pessoas.

\section{SÍNDROME DOS EDIFÍCIOS DOENTES}

Fatores históricos complexos da civilização, como a revolução industrial, a mecanização da agricultura, as revoluções da informática e dos serviços, obrigam o ser humano moderno a viver a maior parte do tempo no interior das edificações. Com a concentração das pessoas nas cidades, as condições de salubridade dos ambientes interiores aos edifícios passaram a adquirir importância crescente enquanto influenciadoras do estado de saúde das populações.

As condições de sub-habitação a que são submetidas vastas parcelas dos moradores das cidades constituem-se em causa principal de uma série de doenças, notadamente as de veiculação hídrica. As medidas de higiene adotadas em meio urbano, como o esgotamento sanitário e a água tratada, são os responsáveis diretos pela maior longevidade humana, evitando as epidemias que dizimavam vastas parcelas das populações de maneira periódica (JANSZ, 2011).

Com a invenção do ar-condicionado, o desenvolvimento tecnológico das estruturas de aço e concreto e do elevador, no início do século XX, passou-se a adotar construções verticalizadas, com janelas fechadas ou, mesmo, sem janelas, criando-se ambientes com pouca ou nenhuma troca com o ar exterior, ocasionando reações orgânicas adversas naqueles que os utilizam. A não renovação do ar, que aumenta o índice de gás carbônico, juntamente com a crescente adoção de materiais sintéticos - como colas, resinas e produtos de limpeza -, a falta de manutenção de filtros dos aparelhos insufladores de ar e resíduos de 
fumaça de cigarros acarretam problemas respiratórios e alérgicos associados ao ambiente construído (FINNEGAN; PICKERING; BURGE, 1984).

A expressão Sick Building Syndrome (SBS) - ou Síndrome do Edifício Doente (SED) - foi cunhada para expressar problemas de saúde ocasionados pelas condições ambientais dos espaços reservados ao trabalho diário. Observou-se que algumas pessoas são acometidas de sensações como dores de cabeça, náuseas, tonturas, problemas respiratórios e outras afecções somente enquanto estão no ambiente de trabalho. A característica principal da doença é a relação dos sintomas com o ambiente, que desaparecem depois de poucas horas que o indivíduo deixa o local.

Pesquisas mais aprofundadas demonstram que os espaços fechados, submetidos diariamente ao ar condicionado, ou aqueles com deficiência de ventilação, são os mais propensos à disseminação dessa patologia. A partir da década de 1980, diversas pesquisas foram efetuadas em ambientes de trabalho que utilizavam o ar-condicionado durante todo o dia, detectando-se, por parte de uma parcela dos usuários, os sintomas. Com a continuidade desses estudos, foi demonstrado que outros fatores também seriam determinantes do malestar dos ocupantes das edificações, como os ruídos intensos e continuados, a falta de janelas que permitissem a visão exterior, entre outras características.

Analisando mais de trezentos trabalhos relativos à questão da ventilação em escritórios, Sundell, Levin e Novosel (2006) detectaram que haviam poucos casos de notificação da síndrome apenas quando a troca de ar excedia a 25 litros por segundo por pessoa. Schettler (2006, p.4) constata a efetividade do aumento da troca de ar a partir de 10 litros por segundo por pessoa, na melhoria das condições internas do ar em escritórios. Wargocki, Wyon e Fanger (2000) demonstram uma forte correlação entre qualidade do ar e produtividade em ambientes de trabalho.

Segundo Naimi (2013, p. 29), as condições mais frequentes para a detecção da SED são: falta de ventilação, proximidade de ruas barulhentas, alta umidade, execução de obras e mobiliário que utiliza resinas sintéticas. Graudenz e Dantas (2007) constatam que a maior incidência da SED foi detectada em edifícios recém-inaugurados (até seis meses) e nos mais antigos. Nos edifícios mais novos, considera-se a causa mais provável a exalação de resinas de mobiliário e carpetes e, nos mais antigos, a falta de limpeza de filtros de ar condicionado. 
A pesquisa sobre o tema continua a despertar grande interesse em relação à melhoria das condições de bem-estar no interior das edificações. As informações disponíveis servem para comprovar a influência direta das condições do ambiente construído na saúde dos seus ocupantes. Passam-se grandes períodos da vida diária no interior de edifícios, recebendo-se continuamente sua influência. Nada mais justo que a preocupação com esses ambientes seja decisiva para o estado de saúde dos usuários.

As condições de trabalho e habitação devem ser consideradas na avaliação da qualidade do espaço construído. Deve-se priorizar a adequação ambiental em qualquer projeto arquitetônico ou obra. Com o claro desafio proporcionado pelas mudanças climáticas, que colocam em jogo a sobrevivência da espécie humana, a concepção de edifícios saudáveis torna-se primordial, significando um avanço qualitativo útil para toda a sociedade.

\section{EDIFÍCIOS SAUDÁVEIS}

Pode-se qualificar um edifício como ambientalmente equilibrado se não provocar doenças. É famosa a frase de Florence Nightingale (1863), referindo-se aos hospitais, no prefácio de seu livro: "Pode parecer um princípio estranho declarar como o primeiro requisito em um Hospital que não deve fazer ao enfermo nenhum dano." (NIGHTINGALE, 1863, p. iii). Essa característica, contudo, não pode ser suficiente para os edifícios de saúde. Para esses estabelecimentos, o ambiente deve ser agradável, convidativo, indutor do relaxamento, tranquilidade e alegria, deve ser um espaço curativo, saudável. De meados do século XIX até o início do século XX, quando da implantação do partido pavilhonar em hospitais, observou-se um período em que as edificações eram consideradas verdadeiras "máquinas de curar", dando-se o devido destaque à questão ambiental. O progresso tecnológico, no entanto, acabou por sufocar esse paradigma (TOLEDO, 2006).

A urbanização do mundo moderno, com seu progresso material crescente, levou a medicina a priorizar o tratamento baseado em medicamentos sintetizados, esquecendo-se do papel essencial das condições ambientais para a recuperação dos pacientes. Deve-se destacar que a cura, antes de tudo, é um processo natural (GUENTHER; VITTORI, 2008, p.77). 
A medição dos aspectos ambientais positivos não se trata de tarefa simples. Não há, porém, espaço arquitetônico mais indicado para a análise das suas qualidades curativas que as edificações assistenciais de saúde e, em particular, os hospitais, que têm a característica de internar doentes, muitas vezes por longos períodos. Nesses lugares, as pessoas se encontram debilitadas, sendo mais sensíveis aos aspectos positivos da edificação. Se as causas da SED atuam sobre indivíduos sadios, serão ainda mais rigorosas sobre os debilitados. A pesquisa ambiental em edificações de saúde indica, para as demais tipologias de edificações, quais as características físicas favoráveis, não somente para a manutenção e indução do bem-estar, mas para a cura.

As pesquisas relativas aos ambientes de saúde já possuem um volume quantitativo e qualitativo que permite interessantes conclusões sobre as características de um edifício saudável. Alguns desses estudos foram executados segundo a metodologia do "projeto baseado em evidências" ou evidence based design. Essa designação tem sido dada a uma corrente neopositivista de pesquisas na medicina que defende a comprovação quantitativa dos procedimentos curativos e critica uma série de considerações baseadas apenas no senso comum, sem nenhuma comprovação de dados rigorosamente coletados. Malkin (2012) afirma que já é possível listar diversas características ambientais como de influência quantitativamente comprovada no restabelecimento da saúde de pessoas internadas em hospitais, como o uso da iluminação natural, que diminui os erros médicos; as vistas da natureza, que diminuem a dor e a redução de ruído, que auxilia no tratamento de casos de depressão (MALKIN, 2012, p. 20).

De acordo com Verderber (2010, p. 67), a gestão ambiental curativa em uma edificação de saúde está ligada ao controle das condições climáticas, à utilização da iluminação natural, à facilidade de manutenção e reforma e ao proporcionar visuais agradáveis e o convívio com a natureza.

Os fatores que afetam positivamente a saúde dos usuários de um estabelecimento de saúde podem ser considerados características desejáveis dos edifícios saudáveis. Nos estudos efetuados na literatura sobre o tema, observa-se que esses fatores podem ser englobados em três setores: Higiene, Conforto e Sustentabilidade. 


\section{HIGIENE}

Em relação à higiene da edificação, o primeiro ponto que se destaca nos estabelecimentos de saúde é a necessidade de controle de infecção. As Infecções Relacionadas à Assistência à Saúde (IRAS) constituem-se em permanente preocupação dos órgãos responsáveis pela vigilância sanitária. Não existem dados atualizados fidedignos sobre a incidência de infecção hospitalar no Brasil, mas Monteiro e Pedroza (2015) reportam uma pesquisa realizada em 1995, em 103 hospitais brasileiros de diversas capitais, onde foi encontrado um índice de 15,5\%, sendo de 18,6\% em instituições públicas. Acrescentam, ainda, que um estudo da OPAS/OMS descreve uma pesquisa executada em 14 países, no período entre 1986 e 1985, onde foi encontrada uma taxa de infecção hospitalar de 8,7\%.

O controle de infecção é um problema de grande magnitude, que interfere nos serviços prestados em ambientes de saúde, colocando em risco não somente o paciente, mas visitantes e funcionários. Deve-se adicionar à questão a crescente resistência dos microorganismos aos antibióticos, fato que torna a simples frequência aos hospitais um fator de risco.

A principal forma de transmissão de infecções é o contato físico entre pessoas ou com equipamentos contaminados. Essa característica torna a questão da lavagem das mãos o principal requisito para o seu controle, impondo-se a necessidade de colocação estratégica, e em quantidade suficiente, de lavatórios e dispensadores de álcool gel. Fiorentini, Lima e Karman (1995) ressaltam a necessidade de colocação de lavatórios também em locais de confecção e consumo de alimentos e junto a instalações sanitárias.

De acordo com Prado, Hartmann e Teixeira Filho (2013), a baixa adesão à lavagem das mãos nos hospitais brasileiros se deve à falta de treinamento continuado das equipes de saúde, escassez de lavatórios e sua má localização, carência de produtos de limpeza, falta de cultura de higiene e limpeza e liderança administrativa que incentive o procedimento.

Correlacionado ao controle de infecção hospitalar, está a escolha de materiais de acabamento de pisos, paredes e tetos. A correta seleção dos materiais de acabamento e mobiliário é tarefa de especial importância em um estabelecimento de saúde, pois determina a facilidade de limpeza, durabilidade e eficiência da manutenção. Os materiais de acabamento utilizados em estabelecimentos de saúde sofrem ação constante de produtos químicos cáusticos e abrasivos. A sua durabilidade envolve não somente a resistência, mas a 
manutenção que não implique em trocas ou reparos frequentes. Deve ser acrescentada, ainda, a absorção acústica, que interfere no conforto, principalmente de pacientes internados; a aparência estética, que influencia decisivamente no bem-estar dos usuários, e o custo, que permita sua aquisição e reparo (BICALHO, 2010, p. 75).

A RDC 50/2002 (BRASIL, 2004) divide os ambientes de um estabelecimento de saúde em áreas críticas, semicríticas e não críticas, quanto aos cuidados de controle de infecção. As áreas críticas são onde se dispensam cuidados a pacientes que estejam em risco de vida como em cirurgias, emergências, terapia intensiva, hemodiálise, hemodinâmica - ou serviços de apoio à vida - como laboratórios, cozinha e lactário.

Em áreas críticas, frequentemente há a necessidade de limpeza devido ao derramamento de sangue, secreções ou medicamentos. Bicalho (2010) destaca que pisos em áreas críticas devem ter a menor absorção possível de água, que facilita a proliferação de micro-organismos. A RDC 50/2002 (BRASIL, 2004, p. 120) estipula um índice de absorção de água máximo para pisos em áreas críticas de $4 \%$. Essas áreas possuem necessidade de proteção ambiental, assim como podem representar risco para outros ambientes. Os projetos desses espaços devem ser tratados de forma diferenciada, com a utilização de materiais fáceis de limpar, que resistam a produtos ácidos e básicos, além de terem alta confiabilidade técnica e resistência ao choque e desgaste.

As áreas semicríticas abrigam pacientes ou serviços de baixo risco, como ambulatórios, quartos, enfermarias ou salas de exames não invasivos, como radiologia. Nesses ambientes, os materiais utilizados devem possuir a qualidade de fácil assepsia, mas não necessitam do mesmo nível de limpeza e desinfecção das áreas críticas. Já as áreas não críticas, como depósitos, áreas administrativas e sanitários gerais, não precisam de maior cuidado que qualquer edificação.

Em relação à questão do ruído, devem-se evitar materiais de acabamento refletores de som em locais de estadia prolongada de pessoas, como internações e esperas. Isolamentos acústicos devem ser seriamente considerados em casos de equipamentos médicos ruidosos (BRASIL, 2014).

Uma característica particular dos estabelecimentos assistenciais de saúde é a geração de resíduos sólidos contaminados ou especiais, que exigem, na maioria das vezes, coleta e tratamento diferenciado. A norma RDC 306/2004 (BRASIL, 2006) trata detalhadamente dos 
diversos tipos de resíduos de saúde e especifica a necessidade de que cada instituição possua um plano que garanta a correta segregação na produção do resíduo, bem como a guarda e destino final. Como exemplos de resíduos de saúde particularmente perigosos, pode-se destacar os infectados, as peças anatômicas, os medicamentos e os elementos radioativos. Todos devem ser alvo de correta separação no momento de sua produção, além de ter destino final específico.

A segregação e coleta dos resíduos sólidos de serviços de saúde é um fator importante a ser considerado no projeto de uma edificação de saúde, com a previsão de depósitos para a guarda provisória. A separação por tipo de resíduo deve ser efetuada na geração, conforme as características de risco à saúde pública. Como o destino final dos resíduos perigosos são repassados a empresas especializadas, que possuem contratação custosa, em alguns hospitais de maior porte são projetadas unidades de tratamento simplificadas, que executam a triagem, esterilização e trituração dos resíduos que, dessa forma, perdem a patogenicidade e podem ser descartados ordinariamente. Os abrigos, internos e externos, devem prever separação sinalizada para os resíduos potencialmente infectantes, químicos, perfurocortantes e anatômicos, além das características de acessibilidade, exclusividade, segurança e facilidade de higienização (BRASIL, 2006, p.48).

\section{CONFORTO}

O esforço para criar um espaço humanizado e saudável deve atender aos aspectos de conforto ambiental, ergonômico, de acessibilidade, segurança, sinalização e, principalmente, valorizar as questões subjetivas do usuário, dando confiança àqueles que os utilizam.

A questão da acessibilidade em uma edificação de saúde não se restringe à disponibilização de condições de utilização satisfatória por pessoas portadoras de deficiências - grande parte dos usuários de edificações de saúde -, mas devem adequar-se a casos especiais, como ao trânsito de macas, o transporte de pessoas juntamente com os equipamentos de tratamento, além de prever situações que envolvem a segurança contra acidentes e incêndio. Além de atender à NBR-9050 (ABNT, 2015), deverá observar o que estipula a RDC-50/2002 (BRASIL, 2004) e outras normas, como a NBR-9077 (ABNT, 2001). 
Pacientes internados por longos períodos em hospitais frequentemente têm o ciclo circadiano prejudicado pela iluminação artificial inadequada, pois o corpo humano se adapta ao período da luz solar para dormir, descansar e desempenhar suas atividades. A luz do sol tem atuação no conforto mental, dando sensações de segurança e tranquilidade, o que se reflete na recuperação do paciente. A radiação solar que atinge a pele, não gera somente a vitamina $\mathrm{D}$, necessária para o equilíbrio ósseo e imunológico, mas favorece a produção de um conjunto de hormônios que dão equilíbrio ao comportamento humano (CARDOSO, 2012).

Uma tendência nos estabelecimentos de saúde é a adoção de áreas verdes e o cuidado paisagístico, induzindo ao contato com a natureza. A deambulação precoce é incentivada com a criação dos chamados "jardins terapêuticos", que apresentam vantagens nas unidades de internação hospitalar, como permitir o recebimento de luz solar, o treinamento dos sentidos, a socialização com outros pacientes, diminuindo a tensão nervosa e aumentando a aceitação do tratamento (MARCUS, 2006). Del Nord (2011, p. 622) afirma que será preciso uma atenção particular ao se planejar a máxima utilização da luz natural e do contato com o verde em estabelecimentos de saúde.

Para Hamilton e Shepley (2010), os jardins em unidades de saúde devem considerar a mobilidade reduzida dos pacientes e a criação de áreas para a interação social, para a fruição visual e a introspecção. Janelas amplas, pátios ou varandas podem ser utilizados para esse fim. Guenther e Vittori (2008) destacam a importância de proporcionar vistas que tenham a presença da água, que possui um efeito tranquilizador.

Outro fator essencial no conforto de usuários de estabelecimentos de saúde é sua adequação ergonômica (BRASIL, 2014). Os espaços, mobiliário e equipamentos devem estar adequados ao uso, de modo a proporcionar a manipulação correta e que não traga sequelas. Pode-se destacar, nesse item, o transporte de pacientes e insumos, a utilização de cadeiras, mesas, bancadas e a operação de esquadrias. Os estabelecimentos de saúde necessitam, com frequência, levar indivíduos que não estão em condições de se deslocar sozinhos para que efetuem diversas atividades. A disponibilização de guinchos, móveis ou adaptados em tetos, evita o esforço excessivo do paciente e do pessoal de enfermagem, o que pode ocasionar acidentes ou lesões. 
As cadeiras, mesas e bancadas são comuns em vários espaços de prestação de serviços de saúde. Como o pessoal de enfermagem e pacientes possuem porte físico variável, e o trabalho nesse tipo de mobiliário exige tempo e esforço intenso, será necessário que tenha a possibilidade de adaptação a cada pessoa. 0 mesmo pode-se ressaltar em relação à operação de esquadrias, como portas e janelas, que não devem possuir fechos que dificultem a ação de pessoas com deficiências.

\section{SUSTENTABILIDADE}

O conceito de sustentabilidade na arquitetura, aplicado aos dias hoje, se refere à capacidade da edificação controlar os seus resíduos em geral e o consumo de insumos, de forma que a sua contribuição ao meio ambiente não comprometa gerações futuras (BITENCOURT, 2006, p. 30). A exploração desenfreada dos recursos naturais e a produção de resíduos, notadamente na geração de energia, demonstram uma atuação predatória do ser humano em relação ao meio ambiente, fazendo com que o seu equilíbrio se torne insustentável.

Entre as medidas necessárias para a redução do impacto ambiental de estabelecimentos de saúde, podem ser citados: o controle, reaproveitamento e reciclagem dos resíduos sólidos, como já ressaltado, o aproveitamento da ventilação e iluminação naturais e o incentivo à geração de energia de forma limpa. Não poderá ser esquecido o processo de gerenciamento da construção dos edifícios. As obras deverão atender às condições da construção "mais limpa", de forma a proporcionar a mínima geração de resíduos e a utilização de produtos ecologicamente atestados (CARRAMENHA, 2010). Uma edificação saudável deverá garantir a utilização de materiais em que suas condições de fabricação e transporte sejam ambientalmente corretas.

A análise da questão ambiental envolvendo edifícios de saúde é essencial, principalmente devido às suas características de uso de sofisticados equipamentos tecnológicos e alto consumo energético (GUENTER; KARLINER, 2011). As variações climáticas, que ocorrem a nível global, afetam a saúde não somente em relação à maior 
incidência de desastres naturais, mas a uma vasta gama de fatores. Segundo Guenter e Vittori (2008, p. 27): “Certos problemas de saúde são reconhecidamente associados às variações climáticas, poluição do ar, contaminação da água e doenças ocasionadas por diversos vetores, como moscas, mosquitos e roedores."

Bitencourt (2006, p. 31) destaca que o impacto ambiental de estabelecimentos de saúde está atrelado a características como: funcionamento intensivo nas 24 horas, geração de circulação de pessoas em grande número, possuir distintos centros de trabalho, com demandas de insumos e energia diferenciados, exigindo reserva e grande magnitude de instalações. Pode-se acrescentar ainda: os sistemas construtivos, sua manutenção, fatores de humanização e de segurança sanitária ou biossegurança.

Edificações de saúde são grandes consumidoras de insumos como energia e água. Por frequentemente funcionar nas 24 horas do dia e possuir diversos setores que não podem prescindir em nenhum instante do abastecimento energético, as unidades de saúde mais complexas são obrigadas, por norma, a possuir geradores, baterias e condição segura de fornecimento. Essas características induzem a adoção de sistemas alternativos de geração, como a solar e eólica. 0 pré-aquecimento da água por energia solar já pode ser considerado comum em grandes hospitais, bem como a geração por combustíveis alternativos, como o GLP.

Em relação à economia de energia, deve-se destacar particularmente a busca pela utilização de meios naturais de aquecimento e ventilação. Devido à importância do gasto energético de equipamentos de controle de temperatura, ventilação e umidade, qualquer alteração nessa variável representa grande economia. Soluções arquitetônicas, como a boa orientação do edifício, brises, vidros especiais, teto verde, fachadas ventiladas, isolamentos térmicos em paredes e tetos, podem ser decisivas em relação aos custos de manutenção e à contribuição social aos esforços de menor emissão de $\mathrm{CO} 2$. Os tetos verdes, em especial, auxiliam no isolamento térmico e captação de água da chuva, além de proporcionar espaços adicionais para o lazer de funcionários e pacientes (VILAS-BOAS, 2011).

O alto consumo de água nos estabelecimentos de saúde impõe que sejam considerados como essenciais o seu tratamento para reuso, as diversas formas de economia e o aproveitamento de água da chuva. o tratamento dos efluentes líquidos, principalmente 
os provenientes de laboratórios, lavanderias e de cuidados com os pacientes, constitui-se em medida necessária para a diminuição do impacto ambiental.

Algumas unidades de saúde, como hemodiálise e laboratórios, necessitam de tratamento adicional da água antes do consumo, o que pode ser estendido a toda edificação, a depender da fonte de fornecimento. Seus reservatórios devem ter controle frequente de qualidade, garantida por exames laboratoriais. A quantidade e volume de câmaras de reserva de água potável deverá permitir o fornecimento contínuo, mesmo nos momentos em que se efetuar a manutenção, limpeza, desinfecção e controle de qualidade.

\section{CONCLUSÕES}

Para a determinação das características de uma edificação saudável, o melhor modelo a ser estudado são as edificações de saúde, notadamente os hospitais. Nesses estabelecimentos é possível efetuar medições e analisar os meios físicos que favorecem a cura. Essas condições certamente serão úteis para pessoas saudáveis terem um espaço equilibrado e apto à preservação de suas condições físicas e mentais.

No quadro 01, pode-se observar um resumo das características mais relevantes aqui levantadas para uma edificação saudável, indicando um caminho para a análise e confecção de projetos arquitetônicos indutores de bem-estar físico e mental.

As características de Higiene, Conforto e Sustentabilidade podem ser consideradas os pilares de uma edificação que, além de não provocar danos ao ambiente, permita o restabelecimento da saúde de pessoas que eventualmente estejam debilitadas - e isso é particularmente importante na atualidade, quando se experimenta um aumento acelerado da expectativa de vida, o que implica na maior quantidade de pessoas idosas e com problemas de saúde. 
Quadro 1: Características do Edifício Saudável

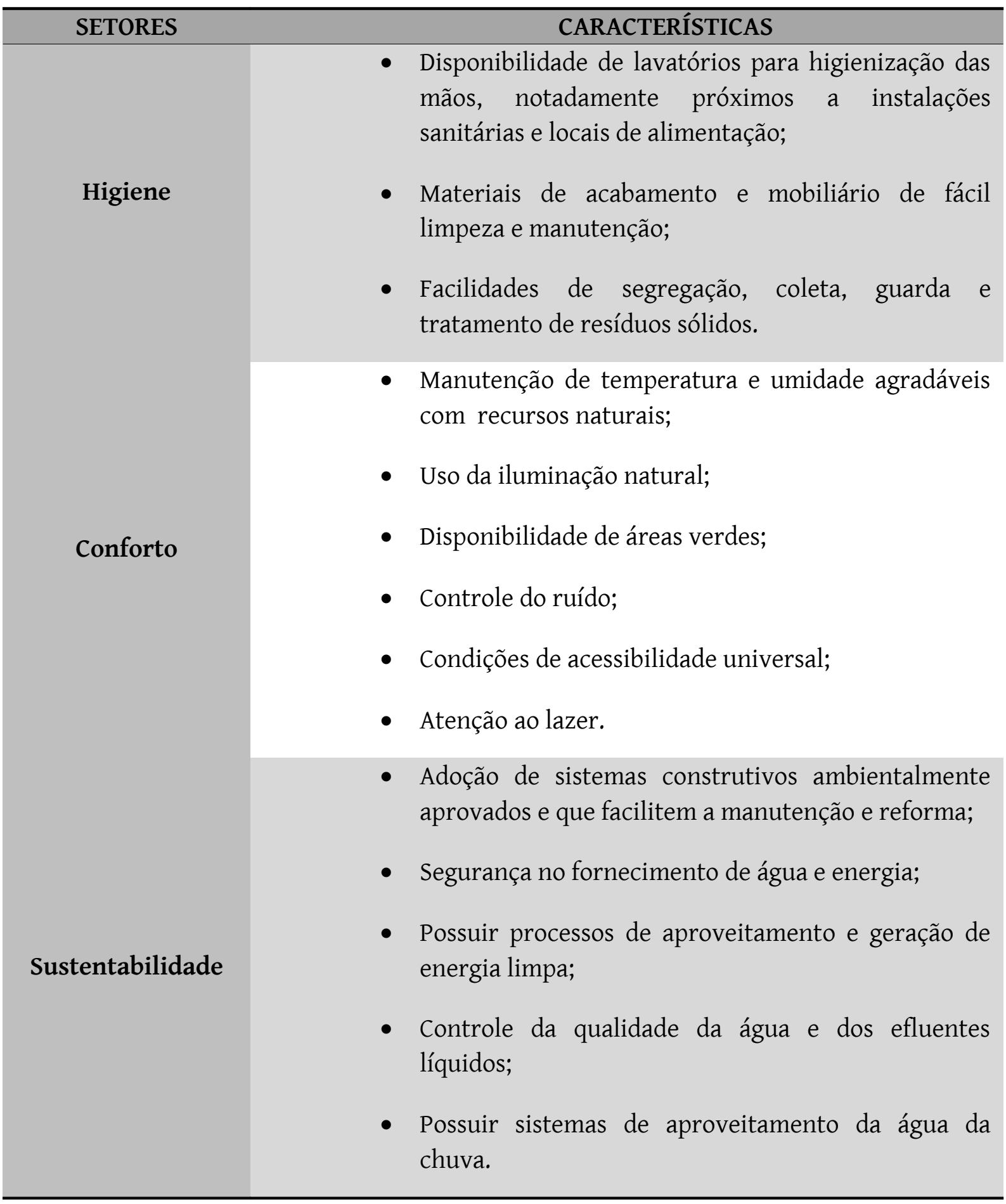

Fonte: autor

Logicamente a higiene será essencial em um edifício saudável. Os estabelecimentos de saúde indicam que será essencial a disponibilização, em locais estratégicos, de lavatórios, que induzam a lavagem das mãos - principal forma de diminuição da transmissão de 
infecções. A proximidade de instalações sanitárias e locais de alimentação são os pontos naturalmente indicados em todo tipo de edificação.

Os materiais de acabamento em pisos paredes e tetos e as superfícies do mobiliário deverão favorecer a limpeza e a manutenção. Aos resíduos gerados pelas atividades desempenhadas nas edificações serão previstos locais adequados para a segregação, guarda e coleta, facilitando o tratamento posterior.

Quanto ao conforto, a edificação saudável deverá permitir a conservação da temperatura e umidade agradável utilizando o mínimo de recursos artificiais. A iluminação e ventilação naturais devem ser incentivadas, com a adoção das técnicas de proteção disponíveis. As áreas verdes precisam ser utilizadas não somente para o conforto visual, mas como locais de socialização e caminhadas, facilitando os banhos de sol e o desfrute do ar puro. O ruído deve ser combatido, tomando-se as medidas de isolamento adequadas. Faz parte da edificação saudável a adoção do princípio da acessibilidade universal, considerando que todos possuem períodos da vida em que estão com alguma incapacidade física.

O que as edificações de saúde acrescentam em relação à sustentabilidade ambiental são as medidas que garantam o pleno fornecimento, sem interrupções, dos insumos básicos de água e energia. A existência de formas seguras de armazenamento da água, bem como o incentivo à geração de energia limpa, são lições dos estabelecimentos de saúde para as edificações saudáveis. Pode-se, ainda, acrescentar o cuidado com o tratamento de efluentes contaminantes que despejem em mananciais.

O estudo continuado das melhores condições ambientais das edificações de saúde será essencial para o estabelecimento de ambientes saudáveis para todos os seres humanos. Um edifício saudável deve induzir a hábitos corretos, que mantenham o perfeito equilíbrio físico, mental e social do ser humano, desenvolvendo formas dinâmicas de participação das comunidades em que se inserem. 


\section{REFERÊNCIAS}

ABNT - ASSOCIAÇÃO BRASILEIRA DE NORMAS TÉCNICAS. NBR 9050: Acessibilidade a edificações, mobiliário, espaços e equipamentos urbanos. Rio de Janeiro, 2015.

ABNT - ASSOCIAÇÃO BRASILEIRA DE NORMAS TÉCNICAS. NBR 9077: Saídas de emergência em edifícios. Rio de Janeiro, 2001.

BATISTELLA, Carlos. Saúde, Doença e Cuidado: complexidade teórica e necessidade histórica. Disponível em: http://www.epsjv.fiocruz.br/pdtsp/index.php?

s_livro_id=6\&area_id=2\&capitulo_id=13\&autor_id=\&sub_capitulo_id=14\&arquivo=ver_conteudo_2. Acesso em: 10 jun 2017.

BICALHO, Flávio C. A arquitetura e engenharia no controle das infecções. Rio de Janeiro: Rio Books, 2010.

BITENCOURT, Fábio. A sustentabilidade em ambientes de serviços de saúde: um componente de utopia ou de sobrevivência? In: CARVALHO, Antonio Pedro Alves de. (Org.). Quem tem medo da Arquitetura Hospitalar? Salvador: Quarteto Editora, 2006. p.13-48.

BRASIL. Agência Nacional de Vigilância Sanitária (ANVISA). Conforto Ambiental em Estabelecimentos Assistenciais de Saúde. Brasília, 2014.

BRASIL. Agência Nacional de Vigilância Sanitária (ANVISA). Manual de gerenciamento de resíduos de serviços de saúde. Brasília, 2006.

BRASIL. Agência Nacional de Vigilância Sanitária (ANVISA). Normas para projetos físicos de estabelecimentos assistenciais de saúde. Resolução RDC/ANVISA no 50, de 21 de fevereiro de 2002. 2a. ed. Brasília, 2004.

CARDOSO, João D. Luminárias especiais para ambientes hospitalares de internação prolongada. In: CONGRESSO BRASILEIRO PARA O DESENVOLVIMENTO DO EDIFÍCIO HOSPITALAR, 5, 2012, São Paulo. Anais... São Paulo. 2012, p. 59-66.

CARRAMENHA, Márcia Maria Lisbôa. Sustentabilidade em edifícios de saúde. In: CONGRESSO BRASILEIRO PARA O DESENVOLVIMENTO DO EDIFÍCIO HOSPITALAR, 4, 2010, Brasília. Anais... Brasília, 2010, p. 71-82.

DEL NORD, Romano. The New Strategic Dimensions of the Hospital of Excellence. Firenze: Polistampa, 2011.

FINNEGAN, M.J.; PICKERING, C.A.C.; BURGE, P. S. The sick building syndrome: prevalence studie. British Medical Journal, London, v. 289, n. 8, December, 1984.

FIORENTINI, Domingos M. F.; LIMA, Vera H. A.; KARMAN, Jarbas B. Arquitetura na prevenção de infecção hospitalar. Brasília: Ministério da Saúde, 1995. 
GRAUDENZ, Gustavo S.; DANTAS, Eduardo. Poluição dos ambientes interiores: doenças e sintomas relacionados às edificações. Revista Brasileira de Medicina. Ano 2, n.1, fev. 2007. Disponível em: http://www.moreirajr.com.br/revistas.asp?fase=r003\&id_materia=3497. Acesso em: 25 jun 2016.

GUENTHER, R.; VITTORI, G. Sustainable Healthcare Architecture. New York: John Wiley \& Sons, 2008.

GUENTHER, Robin; KARLINER, Joshua. Agenda Global de Hospitais Verdes e Saudáveis, 2011. Disponível em: <http://greenhospitals.net/wp-content/uploads/2012/03/GGHHA-Portugese.pdf>. Acesso em: 01 mar. 2016.

HAMILTON, D. Kirk; SHEPLEY, Mardelle McCuskey. Design for Critical Care: An Evidence Based Approach. Burlington, MA: Architectural Press - Elsevier, 2010.

JANSZ, Janis. Introduction to Sick Building Syndrome. In: ABDUL-WAHAB, Sabah A. (ed.) Sick Building Syndrome in Public Buildings and Workplaces. London: Springer, 2011, p. 1-24.

MALKIN, Jain. Fulfilling the promise of evidence based design. In: CONGRESSO BRASILEIRO PARA O DESENVOLVIMENTO DO EDIFÍCIO HOSPITALAR, 5, 2012, São Paulo. Anais..., São Paulo, 2012, p. 19-25.

MARCUS, Clare C. Healing Gardens in Hospitals. In: WAGENAAR, Cor (ed.). The architecture of hospitals. Rotterdam: NAiPublishers, 2006. p. 315-329.

MONTEIRO, Tarciane S.; PEDROZA, Robermam M. Infecção Hospitalar: visão dos profissionais da equipe de enfermagem. Revista de Epidemiologia e Controle de Infecção. V.5, n. 2, 2015. p.84-88.

NAIMI, Maryam. Effective of Sick Building Syndrome on Irritation of the Eyes and Asthma. International journal of Advanced Biological and Biomedical Research. Volume 1, Issue 12, 2013, p. 1529-1534.

NIGHTINGALE, Florence. Notes on Hospitals. 3rd ed. London: Longman, 1863.

PRADO, Maria F.; HARTMANN, Talita P.S. ; TEIXEIRA FILHO, Leone A. Acessibilidade da estrutura física hospitalar para a prática da higienização das mãos. Escola Anna Nery Revista de Enfermagem. V. 17, n. 2, 2013, p. 220-226.

SCHETTLER, Ted. Efectos de los edificios sobre la salud: ¿Qué es lo que sabemos? Science and Environmental Health Network. Instituto de Medicina (IOM), 10-11 de janeiro de 2006. Disponível em:

<http://noharm.org/lib/downloads/espanol/Efectos_de_los_Edificios.pdf> Acesso em: 25 jun 2016.

SUNDELL, Jan; LEVIN, Hal; NOVOSEL, Davor. Ventilation rates and health: report of an interdisciplinary review of the scientific literature. Alexandria: National Center for Energy Management and Building Technologies Contact, 2006. 
TOLEDO, Luiz C. Feitos para curar: arquitetura hospitalar e processo projetual no Brasil. Rio de Janeiro: ABDEH, 2006.

VERDERBER, Stephen. Innovations in Hospital Architecture. New York: Routledge, 2010.

VILAS-BOAS, Doris. Sustentabilidade em estabelecimentos assistenciais de saúde: soluções de projeto arquitetônico. Ambiente Hospitalar. São Paulo, v. 5, n. 8, 2011. p. 9-17.

WARGOCKI, P.; WYON, D. P.; FANGER, O. Productivity is affected by the air quality in offices. International Centre for Indoor Environment and Energy, Technical University of Denmark. Proceedings of Healthy Buildings, v. 1, p. 635-640, 2000. Disponível em <http://www.senseair.se/wp-content/uploads/2011/05/1.pdf> Acesso em: 25 jun 2016. 